\title{
FUNGOS E FUMONISINAS NO PERÍODO PRÉ-COLHEITA DO MILHO ${ }^{1}$
}

\author{
Gislaine HERMANNS ${ }^{2, *}$, Flávia T. PINTO², Samira E. KITAZAWA², Isa B. NOLL ${ }^{2}$
}

\begin{abstract}
RESUMO
A contaminação fúngica e por micotoxinas no milho pode ocorrer antes mesmo da colheita, resultando em grandes perdas econômicas. Fusarium spp. é o principal contaminante do milho no campo, e muitas espécies deste gênero são responsáveis pela produção de fumonisinas. As fumonisinas são tóxicas para animais e humanos, estando envolvidas na doença da leucoencefalomalácea eqüina e associadas à síndrome de edema pulmonar em suínos e câncer de esôfago em humanos. O objetivo deste trabalho foi identificar os pontos críticos de contaminação fúngica e a produção de fumonisinas durante o período pré-colheita do milho. Os resultados mostraram um crescimento fúngico já na fase de grão farináceo, com nenhuma diferença significativa nas fases seguintes: grão farináceo duro e maturação fisiológica. Fungos não esporulados foram predominantes na fase de florescimento (100\%) e na fase de grão farináceo (95\%). Espécies saprófitas foram identificadas na fase de grão farináceo duro (23,25\%). Fusarium spp. já foi evidente na fase de grão farináceo (5\%), aumentando consideravelmente nas fases de grão farináceo duro (62,5\%) e maturação fisiológica (90\%). Todas as cepas de Fusarium spp. testadas mostraram-se potencialmente toxigênicas. Fumonisinas foram evidentes nas fases finais de desenvolvimento, aumentando consideravelmente da fase de grão farináceo duro $(0,2 \mathrm{ppm})$ para a maturação fisiológica $(2,5 \mathrm{ppm})$. Os autores sugerem atenção especial e adoção de medidas preventivas na fase de grão farináceo, onde Fusarium spp. começa a ser evidente.

Palavras-chave: fungos, fumonisinas, pré-colheita.
\end{abstract}

\section{SUMMARY}

FUNGI AND FUMONISINS AT MAIZE'S PRE-HARVEST PERIOD. Fungal and mycotoxin contamination in maize can take place even before harvest time, with large economic losses in consequence. Fusarium spp. is a ubiquitous contaminant of corn in the field and several species of this genera are responsible for fumonisins production. Fumonisins are reported to be toxic to animals and humans, implicated in equine leukoencephalomacia disease and associated with pulmonary edema syndrome in swine and esophageal cancer in humans. The objective of this work was to identify critical points of fungal contamination and fumonisins production during pre-harvest growth stage. Results showed fungal growth since the dough stage, with no significant difference at both following stages: dent and physiological maturity. Non sporulated fungi were predominant at the silking stage (100\%) and at the dough stage (95\%). Saprophytes species were identified at the dent stage (23.25\%). Fusarium spp. was evident since the dough stage (5\%) increasing considerably through the dent stage $(62.5 \%)$ to the physiological maturity (90\%). All Fusarium spp. strains tested showed toxigenic potential. Fumonisins were evident at the latest development stages increasing considerably from the dent stage $(0.2 \mathrm{ppm})$ to the physiological maturity $(2.5 \mathrm{ppm})$. Authors suggest special attention and adopting preventive measures in relation to the dough stage, from which Fusarium spp. begin to be evident.

Keywords: fungi, fumonisins, pre-harvest.

\section{1 - INTRODUÇÃo}

Assim como outros grãos, o milho é constantemente exposto a possíveis contaminações fúngicas, as quais podem se iniciar ainda no campo, durante o seu desenvolvimento. Neste caso, a contaminação pode ocorrer pela presença de esporos e fragmentos de micélio presentes no solo, de restos de plantas e sementes, ou ainda serem transportados pelo vento, chuva ou insetos (MILLS, 1989).

Os efeitos do crescimento fúngico incluem diminuição do poder de germinação, emboloramento visível, descoloração, odor desagradável, perda de matéria seca, aquecimento, mudanças químicas e nutricionais, perda de qualidade e produção de compostos tóxicos - as micotoxinas (POMERANZ, 1982). Esta contaminação pode fazer com que os grãos tornem-se impróprios para o consumo humano e animal, resultando em grandes perdas econômicas (PASTER \& BULLERMAN, 1988).

\footnotetext{
${ }^{1}$ Recebido para publicação em 8/2/2004. Aceito para publicação em 23/1/2006 (001291)

${ }^{2}$ Instituto de Ciência e Tecnologia de Alimentos (ICTA). Universidade Federal do Rio Grande do Sul (UFRGS)

Caixa Postal 15.090

CEP 91501-970 - Porto Alegre (RS)

E-mail: gislainehermanns@ibest.com.br

*A quem a correspondência deve ser enviada
}

Dentre os fungos micotoxigênicos envolvidos na cadeia alimentar humana destacam-se os gêneros Aspergillus, Penicillium e Fusarium, os quais são responsáveis pela grande maioria das micotoxinas até hoje conhecidas e estudadas. Enquanto as espécies de Penicillium e Aspergillus são mais comumente encontradas como contaminantes de produtos durante a secagem e armazenamento, as espécies de Fusarium são patógenos da planta, que produzem micotoxinas antes ou imediatamente após a colheita (SWEENEY \& DOBSON, 1998).

Dentro do gênero Fusarium, as espécies fúngicas mais comuns no campo são $F$. verticilioides e $F$. subglutinans, freqüentemente responsáveis pelo apodrecimento de grãos individuais ou de áreas localizadas da espiga de milho e conseqüente produção de fumonisinas.

Frente ao exposto, o presente trabalho objetivou identificar os pontos críticos de crescimento fúngico e produção de fumonisinas durante o período pré-colheita.

\section{2 - MATERIAL E MÉTODOS}

\section{1 - Amostragem}

No período pré-colheita, durante o desenvolvimento fenológico da planta, foram coletadas amostras de milho de cinco diferentes estádios: florescimento, grão 
leitoso/pastoso, grão farináceo, grão farináceo duro e maturação fisiológica.

A fim de se obter uma maior representatividade da lavoura, a mesma foi dividida em quatro quadrantes, constituídos por oito fileiras de milho e $14 \mathrm{~m}$ de comprimento. A coleta das amostras foi realizada de forma aleatória dentro de cada quadrante, em um espaço de $2 \mathrm{~m}$ de comprimento, deixando-se sempre duas fileiras de bordadura de cada lado. A cada nova coleta, correspondente a um novo estádio de desenvolvimento, avançavam-se dois metros dentro de cada quadrante. Um total de dez espigas foi coletado por quadrante, perfazendo um total de quarenta espigas amostradas. As espigas foram acondicionadas em sacos de algodão previamente identificados e encaminhadas ao laboratório de análises micotoxicológicas do Instituto de Ciência e Tecnologia de Alimentos (ICTA).

\section{2 - Metodologia}

As amostras em espiga provenientes do campo foram previamente desinfetadas superficialmente com hipoclorito de sódio $1 \%$. Em seguida, procedeu-se a retirada da palha e o debulhamento das espigas, de forma manual e asséptica. Os grãos foram então homogeneizados em recipiente desinfetado com álcool 70\%, e a amostra total, dividida em sub-amostras para análise micológica, análise de umidade, atividade de água (aw) e análise de micotoxinas.

A análise micológica foi realizada dentro de 24 h após a coleta das amostras. Uma contraprova foi armazenada em vidro estéril, sob congelamento.

As sub-amostras para análise de umidade, atividade de água e micotoxinas foram moídas em moinho de facas, sendo a análise de umidade realizada dentro de 24 h após a coleta. As amostras moídas para micotoxinas e aw foram armazenadas em freezer até o momento da análise.

A umidade das amostras de milho foi determinada empregando o método de secagem em estufa a $105^{\circ} \mathrm{C}$, por três horas, segundo IAL - INSTITUTO ADOLFO LUTZ (1985).

A determinação da atividade de água foi realizada em equipamento TESTO 150, próprio para medição da aw, com controle de temperatura das amostras feita em estufa a $25^{\circ} \mathrm{C}$.

A enumeração de bolores e leveduras presentes nas amostras de milho foi realizada, em duplicata, por meio da técnica de plaqueamento em superfície (ABNT, 1987). Após a contagem das placas, a fim de se obter uma estimativa do percentual de fungos presentes, realizou-se o isolamento das colônias fúngicas em tubos de ágar sabouraud dextrose inclinado (LACAZ, 1991). A identificação dos gêneros predominantes foi realizada com a técnica de microcultivo segundo RIBEIRO \& SOARES (1993) e classificação segundo BARNETT \& HUNTER (1998).

Cepas de Fusarium spp. foram escolhidas aleatoriamente e testadas quanto a sua capacidade de produção de fumonisinas, em cultivo semi-sólido, utilizando como substrato grãos de milho esterilizados e isentos destas micotoxinas. A isenção de fumonisinas foi determinada pela análise dos grãos com kits ELISA (BACON \& NELSON, 1994; WARFIELD \& GILCHRIST, 1999). A partir de cada uma das cepas selecionadas, uma suspensão de esporos foi preparada em água peptonada $0,1 \%$. Os esporos foram contados em Câmara de Neubauer, e o volume necessário para obter-se $2,5 \times 10^{6}$ esporos, foi inoculado em erlenmeyers com $50 \mathrm{~g}$ de meio estéril (milho em grão a $43 \%$ de umidade). Estes foram tampados com algodão e incubados em estufa $\mathrm{DBO}$ a $25^{\circ} \mathrm{C}$ por 30 dias Após este período, $250 \mathrm{~mL}$ de metanol $70 \%$ foi adicionado nos erlenmeyers e as toxinas extraídas, sob agitação a $125 \mathrm{rpm}$ por 15 min (BACON \& NELSON, 1994; WARFIELD \& GILCHRIST, 1999). Uma alíquota de $10 \mathrm{~mL}$ foi coletada para análise de fumonisinas por meio da utilização de kits de imunoensaio Elisa-Competitivo Indireto quantitativo, indicando as cepas potencialmente produtoras destas micotoxinas.

A análise de fumonisinas presentes nos grãos foi também realizada com a utilização de kits de imunoensaio Elisa-Competitivo Indireto quantitativo, servindo como triagem preliminar da contaminação dos grãos no período pré-colheita.

\section{3 - RESULTADOS E DISCUSSÃO}

Na Tabela 1 são apresentados os valores do teor de umidade das diferentes fases de desenvolvimento do milho.

TABELA 1 - Teor de umidade do milho colhido em diferentes fases de desenvolvimento

\begin{tabular}{lc}
\hline Fase de desenvolvimento & Umidade (\%) \\
\hline Florescimento & $88,123^{\mathrm{a}}$ \\
Grão Leitoso/Pastoso & $70,656^{\mathrm{b}}$ \\
Grão farináceo & $48,274^{\mathrm{c}}$ \\
Grão farináceo-Duro & $34,295^{\mathrm{d}}$ \\
Maturação fisiológica & $24,719^{\mathrm{e}}$ \\
\hline
\end{tabular}

Médias seguidas de mesma letra na coluna não diferem, significantemente, pelo teste de Tukey a $5 \%$

Pela análise de variância verificaram-se diferenças significativas entre as fases ( $\mathrm{p}<0,0001)$, mas não entre os quadrantes $(\mathrm{p}=0,65)$. A comparação de médias nas fases de desenvolvimento foi realizada empregando o teste de Tukey a 5\% de probabilidade de erro, que demonstrou haver diferença significativa para umidade entre todas as fases de desenvolvimento (Tabela 1 ).

Os valores de aw obtidos para os grãos de milho nas diferentes fases de desenvolvimento demonstram que este parâmetro manteve-se praticamente constante $(0,92)$ nas fases intermediárias. O valor máximo foi observado na fase de florescimento $(0,95)$ e o mínimo na fase de maturação fisiológica.

Na Tabela 2, são apresentados os valores do crescimento de bolores e leveduras nas fases de desenvolvimento. 
TABELA 2 - Contagem de bolores e leveduras durante as fases de desenvolvimento da planta

\begin{tabular}{lcc}
\hline Fase de desenvolvimento & $\begin{array}{c}\text { Contagem de } \\
\text { bolores } \\
\log (\text { UFC/g) }\end{array}$ & $\begin{array}{c}\text { Contagem de } \\
\text { leveduras } \\
\log (\text { UFC/g) }\end{array}$ \\
\hline Florescimento & $<2^{\mathrm{b}}$ & $1,0000^{\mathrm{b}}$ \\
Grão Leitoso/Pastoso & $1,0000^{\mathrm{b}}$ & $5,7275^{\mathrm{a}}$ \\
Grão farináceo & $5,4600^{\mathrm{a}}$ & $6,4975^{\mathrm{a}}$ \\
Grão farináceo Duro & $5,3700^{\mathrm{a}}$ & $5,8450^{\mathrm{a}}$ \\
Maturação fisiológica & $5,9325^{\mathrm{a}}$ & $5,7700^{\mathrm{a}}$ \\
\hline
\end{tabular}

Médias seguidas de mesma letra na coluna não diferem, significativamente pelo teste de Tukey a $5 \%$ de probabilidade de erro

Como pode ser constatado na Tabela 2 , o crescimento de bolores foi menor na fase de florescimento log<2 UFC/g, ou seja, praticamente não houve crescimento de bolores. O crescimento de leveduras também não ocorreu nesta fase $(\log =1)$. Na fase de grão leitoso/pastoso, em que a aw é alta, em torno de 0,92, o crescimento restringiu-se às leveduras, que necessitam de teores mais elevados de água disponível para se desenvolver (TANIWAKI \& SILVA, 1996). A quantidade e a qualidade de nutrientes existentes nesta fase, constituídos basicamente de açúcares fermentescíveis, também podem ter conduzido a maior predominância de leveduras. Nas fases de grão farináceo e grão farináceo duro, a concentração destes açúcares diminui e a síntese de amido e proteínas aumenta gradativamente até atingir níveis máximos na maturação fisiológica, o que propicia o desenvolvimento de bolores, cujo metabolismo é mais adaptado a substratos ricos em carboidratos complexos (WARFIELD \& GILCHRIST, 1999). Apesar das mudanças na composição de nutrientes favorecer o desenvolvimento de bolores, os altos valores de aw verificados nas fases entre grão farináceo e maturação fisiológica continuaram proporcionando o crescimento de leveduras.

A enumeração de bolores e leveduras durante o período de desenvolvimento do milho na lavoura demonstrou concordância com outros trabalhos em que o crescimento de fungos inicia-se antes mesmo da colheita (CHULZE, et al., 1996). Em relação à identificação dos fungos observouse haver predominância dos não esporulados na fase de florescimento (100\%) e na fase de grão farináceo (95\%), continuando a ocorrer, mas em menor proporção, nas fases de grão farináceo duro ( $14,25 \%)$ e maturação fisiológica (5\%). Fungos saprófitas como Cladosporium, Helminthosporium e Alternaria, aqui classificados como outros, estiveram presentes na fase de grão farináceo duro (23,25\%). Na fase de grão farináceo, na qual a aw ainda é alta 0,92, ótima para o desenvolvimento de fungos de campo (TANIWAKI \& SILVA, 1996), e a constituição do grão é basicamente amido e proteínas, indispensável para o metabolismo de bolores (WARFIELD e GILCHRIST, 1999), o gênero Fusarium spp. (Figuras 1 e 2 ) começou a se desenvolver (5\%), aumentando consideravelmente nas fases de grão farináceo duro (62,5\%) e maturação fisiológica (90\%).

Observa-se, pelo teste de Tukey a 5\%, que não há diferença significativa entre as fases de grão farináceo, grão farináceo duro e maturação fisiológica para a variável contagem de bolores. Pode-se inferir desta análise que a fase de grão farináceo constitui-se, nas condições do experimento, em um ponto crítico de controle no que diz respeito ao crescimento de bolores, uma vez que a contaminação que ocorre nesta fase não muda significativamente nas fases subseqüentes, tornando-se assim necessário adotar medidas que controlem a contaminação fúngica a partir desta etapa.

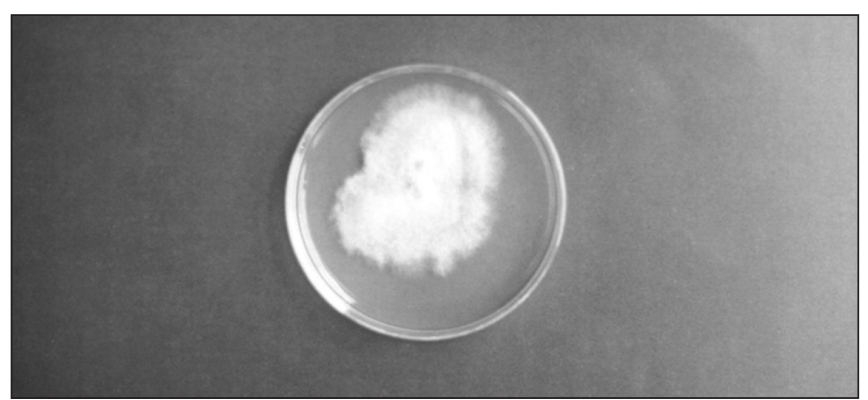

FIGURA 1 - Colônia de Fusarium spp. em ágar batata dextrose

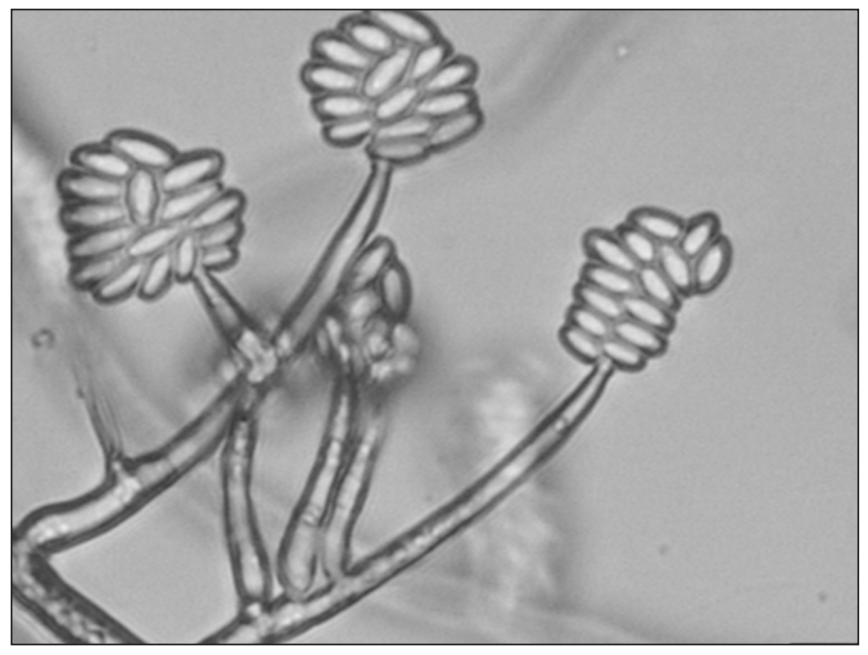

FIGURA 2 - Microcultivo de Fusarium spp. aumento de $800 \mathrm{X}$.

Utilizando milho como substrato, cepas de Fusarium spp. foram testadas quanto à capacidade de produzir micotoxinas. Os resultados obtidos por kits de imunoensaios quantitativos ELISA-Competitivo Indireto, revelaram que $100 \%$ das cepas testadas possuíam a capacidade de produzir fumonisinas. A média de produção encontrada para as cepas isoladas das três fases de desenvolvimento, onde Fusarium spp. se mostrou presente (grão farináceo, grão farináceo-duro e maturação fisiológica) foi de 11 ppm.

A presença de fumonisinas não foi detectada nas fases iniciais de desenvolvimento. Este resultado está de acordo com o encontrado por MACHINSKI \& SOARES (2000), que não verificaram contaminação por fumonisinas $\mathrm{B}_{1} \mathrm{e} \mathrm{B}_{2}$, em amostras de milho verde em espigas (característico da fase de grão leitoso/pastoso).

Os resultados obtidos mostram a presença de fumonisinas nas fases finais do desenvolvimento, com um aumento considerável da fase de grão farináceo-duro $(0,2 \mathrm{ppm})$ para a maturação fisiológica $(2,5 \mathrm{ppm})$, conforme mostra a Figura 3. Estes dados estão de acordo com os obtidos 
por CHULZE et al (1996) e por WARFIELD \& GILCHIRIST (1999), que também detectaram uma maior produção de fumonisinas na fase de maturação fisiológica e em milho recém-colhido.

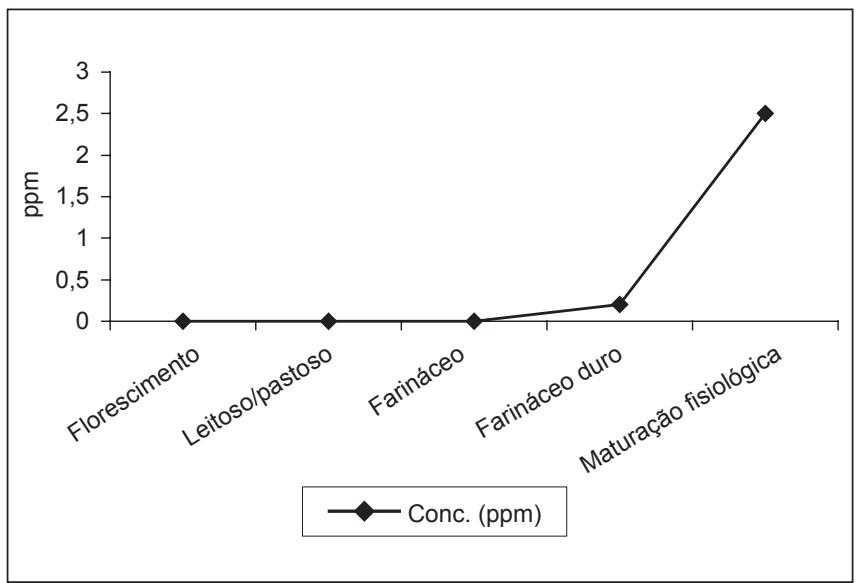

FIGURA 3 - Produção de fumonisinas durante o desenvolvimento do milho

Apesar dos resultados obtidos neste experimento indicarem a presença de fumonisinas nas últimas duas fases de desenvolvimento, a identificação de cepas potencialmente toxigênicas na fase de grão farináceo serve de alerta para a necessidade de medidas preventivas, já nesta fase. Fica evidenciado assim que esta fase pode ser indicada como um ponto crítico de controle, do ponto de vista micotoxicológico, por constituir-se no marco inicial da produção de fumonisinas.

\section{4 - CONCLUSÕES}

A partir dos resultados obtidos conclui-se que a fase de grão farináceo constitui-se, nas condições deste experimento, em um ponto crítico de controle no que diz respeito ao crescimento de bolores e à produção de fumonisinas, servindo de alerta para a necessidade da adoção de medidas preventivas do ponto de vista micotoxicológico.

\section{5 - REFERÊNCIAS BIBLIOGRÁFICAS}

[1] ABNT - ASSOCIAÇÃO BRASILEIRA DE NORMAS TÉCNICAS. Alimentos: contagem total de bolores e leveduras em placas, v. 1, 1987.
[2] BACON, C.W.; NELSON, P.E. Fumonisin Production in corn by toxigenic strains of Fusarium moniliforme and Fusarium proliferatum. Journal of Food Protection. Washington, v. 57, n. 6, p. 514-521, 1994.

[3] BARNETT, H.L.; HUNTER, B.B. Illustrated Genera of Imperfect Fungi, $4^{\text {th }}$ ed. Minnesota: The American Phytopathological Society, 218 p., 1998.

[4] CHULZE, S.N.; RAMIREZ, M.L.; FARNOCHI, M.C.; PASCALE, M.; VISCONTI, A.; MARCH, G. Fusarium and fumonisin occurence in Argentinian corn at different ear maturity stages. Journal of Agricultural and Food Chemistry, v. 44, p. 2.797-2.801, 1996.

[5] IAL - INSTITUTO ADOLFO LUTZ. Normas Analíticas do Instituto Adolfo Lutz, p. 312, 1985.

[6] LACAZ, C.S. Micologia Médica, 1991.

[7] MACHINSKI, M.J.; SOARES, L.M.V. Fumonisins $B_{1}$ and $\mathrm{B}_{2}$ in Brazilian corn-based food products. Food Additives and Contaminants, v. 17, n. 10, p. 875-879, 1996.

[8] MILLS, J.T. Ecology of mycotoxigenic Fusarium Species on cereal seeds. Journal of Food Protection, v. 52, n. 10, p. 737-742, 1989.

[9] PASTER, N.; BULLERMAN, L.B. Mould spoilage and mycotoxins formation in grains as controlled by physical means. International Journal of Food Microbiology, v. 7, n. 3, p. 257-265, 1988.

[10] POMERANZ, Y. Biochemical, functional and nutritive changes during storage. In: CHRISTENSEN, C.M. (ed). Storage of cereal grains and their products, p. 145-217, 1982.

[11] RIBEIRO, M.C.; SOARES, M.M.S.R. Microbiologia Prática: Roteiro e Manual de Bactérias e Fungos, 1993.

[12] SWEENEY, M. J.; DOBSON, A.D.W. Mycotoxin production by Aspergillus, Fusarium and Penicillium species. International Journal of Food Microbiology, v. 43, p. 141-158, 1998.

[13] TANIWAKI, M.; SILVA, N. Fungos deterioradores de alimentos: ocorrência e detecção. Instituto de Tecnologia de Alimentos (Ital), p. 74, 1996.

[14] WARFIELD, C.; GILCHRIST, D.G. Influence of Kernel Age on fumonisin $\mathrm{B}_{1}$ production in maize by Fusarium moniliforme. Applied and Environmental Microbiology, v. 65, n. 7, p. 2.853-2.856. 1999.

\section{6 - AGRADECIMENTOS}

À Coordenação de Aperfeiçoamento de Pessoal de Nível Superior (Capes), aos Drs. Henrique Bartels, Eniltur Viola e Ricardo Martins, da Emater-RS, e ao Sr. Roberto Giovannoni, da Altech do Brasil. 